\title{
Novel markers of human ovarian granulosa cell differentiation toward osteoblast lineage: A microarray approach
}

\author{
MACIEJ BRĄZERT ${ }^{1}$, WIESŁAWA KRANC ${ }^{2}$, PIOTR CELICHOWSKI ${ }^{3}$, KATARZYNA OŻEGOWSKA ${ }^{1}$, \\ JOANNA BUDNA-TUKAN ${ }^{3}$, MICHAL JESETA ${ }^{4}$, LESZEK PAWELCZYK ${ }^{1}$, MAŁGORZATA BRUSKA ${ }^{1}$, \\ MACIEJ ZABEL ${ }^{5,6}$, MICHAŁ NOWICKI ${ }^{3}$ and BARTOSZ KEMPISTY ${ }^{2-4}$
}

\begin{abstract}
${ }^{1}$ Department of Gynecology, Obstetrics and Gynecological Oncology, Division of Infertility and Reproductive Endocrinology, Poznan University of Medical Sciences, 60-535 Poznan; Departments of ${ }^{2}$ Anatomy, and ${ }^{3}$ Histology and Embryology,

Poznan University of Medical Sciences, 60-781 Poznan, Poland; ${ }^{4}$ Department of Obstetrics and Gynecology, University Hospital and Masaryk University, 62500 Brno, Czech Republic; ${ }^{5}$ Department of Human Morphology and Embryology, Division of Histology and Embryology, Wroclaw Medical University, 50-368 Wroclaw;

${ }^{6}$ Division of Anatomy and Histology, University of Zielona Góra, 65-046 Zielona Góra, Poland
\end{abstract}

Received January 16, 2019; Accepted June 26, 2019

DOI: $10.3892 / \mathrm{mmr} .2019 .10709$

\begin{abstract}
Under physiological conditions, human ovarian granulosa cells (GCs), are responsible for a number of processes associated with folliculogenesis and oogenesis. The primary functions of GCs in the individual phases of follicle growth are: Hormone production in response to follicle stimulating hormone (FSH), induction of ovarian follicle atresia through specific molecular markers and production of nexus cellular connections for communication with the oocyte. In recent years, interest in obtaining stem cells from particular tissues, including the ovary, has increased. Special attention has been paid to the novel properties of GCs during long-term in vitro culture. It has been demonstrated that the usually recycled material in the form of follicular fluid can be a source of cells with stem-like properties. The study group consisted of patients enrolled in the in vitro fertilization procedure. Total RNA was isolated from GCs at 4 time points (after 1, 7, 15 and 30 days of culture) and was used for microarray expression analysis (Affymetrix ${ }^{\circledR}$ Human HgU 219 Array). The expression of 22,480 transcripts was examined. The selection of significantly altered genes was based on a P-value $<0.05$ and expression higher than two-fold. The leucine rich repeat containing 17, collagen type I $\alpha 1$ chain, bone morphogenetic protein 4 , twist family bHLH transcription factor 1, insulin like growth factor binding protein 5, GLI family zinc finger 2 and collagen triple helix repeat containing genes exhibited the highest changes
\end{abstract}

Correspondence to: Dr Bartosz Kempisty, Department of Anatomy, Poznan University of Medical Sciences, 6 Święcickiego Street, 60-781 Poznan, Poland

E-mail: bkempisty@ump.edu.pl

Key words: ovarian granulosa, osteoblast, differentiation, microarray, in vitro in expression. Reverse-transcription-quantitative PCR was performed to validate the results obtained in the analysis of expression microarrays. The direction of expression changes was validated in the majority of cases. The presented results indicated that GCs have the potential of cells that can differentiate towards osteoblasts in long-term in vitro culture conditions. Increased expression of genes associated with the osteogenesis process suggests a potential for uninduced change of GC properties towards the osteoblast phenotype. The present study, therefore, suggests that GCs may become an excellent starting material in obtaining stable osteoblast cultures. GCs differentiated towards osteoblasts may be used in regenerative and reconstructive medicine in the future.

\section{Introduction}

A mature ovarian follicle consists of several basic elements that together form one functional unit. Theca externa is located the most externally, followed by theca interna, while granulosa cells (GCs) and oocytes are located inside the ovarian follicle. Several types of follicular GCs are distinguished in the ovarian follicle: Cells lining the inner part of the ovarian follicle, adjacent to the basal lamina are called mural GCs, followed by the layer forming the cumulus oophorus and cells directly surrounding the oocyte-corona radiata. The basic functions of GCs in the individual phases of follicle growth are the production of hormones in response to follicle stimulating hormone $(\mathrm{FSH})$, induction of ovarian follicle atresia through specific molecular markers, as well as the production of nexus cellular connections for communication with the oocyte (1-5). The well-known physiological properties of GCs have influenced the intensive development of fields related to assisted reproduction techniques in humans and animals (6-9).

In recent years, an increase of interest and intense development of domains related to stem cells has been observed. The term 'stem cell' describes cells that have the ability to self-renew and differentiate into more targeted cell types. 
There is a hierarchy of stem cells from those that give rise to all types of cells to those that only differentiate into tissue and organ-specific products. We, therefore, distinguish: Totipotent stem cells-giving rise to embryo cells and extraembryonic tissue; pluripotent stem cells-giving rise to all three germ layers; multipotent stem cells-giving rise to cells from two or one germ layer and unipotent stem cells-tissue-directed, giving rise only to specific cell lines (10). The research suggests that the stem cell reservoir is located in every mature tissue, because cells undergoing apoptosis are continuously replaced by new cells. It is suggested that the biggest stem cell pools are located in the liver, lungs and pancreas (11-15). In terms of clinical approaches, one of the most promising types of such cells are mesenchymal stem cells (MSCs). MSCs are multipotent progenitor cells that have the ability to differentiate towards bone, cartilage and adipose cells. These cells are obtained primarily from fetal tissues (placenta, umbilical cord blood, umbilical cord), also being found in the body of an adult organism (16-19). The main source of adult MSCs in recent years has been the bone marrow and adipose tissue (20). Recent studies indicate that the ovary can also be a source of stem cells. Kossowska-Tomaszczuk et al (21) indicates surprising stem-like properties of GCs. According to her research, GCs in vitro have the properties similar to those of MSCs. Other authors also point out that GCs have stem cell properties, but not as broad as those of MSCs and pluripotent stem cells $(22,23)$. The presented research suggests that GCs, routinely disposed of during the in vitro fertilization procedure, may become a valuable source of cells used to obtain osteoblast populations. Such osteoblasts could be used in the treatment of diseases related to skeletal system pathologies.

\section{Materials and methods}

Part of the material and methods section is based on other publications of the same research team, presenting results from the same cycle of studies related to human ovarian GCs $(24,25)$.

Granulosa cell collection. The study group consisted of 8 patients, aged 18-40 years, enrolled in in vitro fertilization (IVF) procedure in the Division of Infertility and Reproductive Endocrinology, Poznan University of Medical Sciences, Poland. Follicular fluid containing the GCs from patients undergoing in vitro fertilization (IVF) procedures was collected.

The IVF procedure was based on a controlled ovarian hyperstimulation protocol adapted to the patient's initial cause of infertility, as well as predicted and current ovarian response. Stimulation with human recombinant FSH (Gonal-F; Merck-Serono; Merck KGaA) and highly purified human menopausal gonadotropin (hMG-HP; Menopur; Ferring) has been performed according to protocol. Gonadotropin-releasing hormone $(\mathrm{GnRH})$ antagonist-cetrorelix acetate (Cetrotide; Merck-Serono; Merck KGaA), injection has been given at the appropriate dose to suppress the function of the pituitary gland. Induction of ovulation was based on the subcutaneous injection of $6.500 \mathrm{~h}$ of human chorionic gonadotropin (hCG; Ovitrelle; Merck-Serono; Merck KGaA). The doses of gonadotropins and GnRH antagonist have been precisely controlled and recorded for every patient. The follicular fluid has been collected during transvaginal ultrasound-guided oocyte pick-up, $36 \mathrm{~h}$ after administration of human chorionic gonadotropin. GCs have been taken from follicles with a diameter of over $16 \mathrm{~mm}$. Directly after ovarian puncture, the complete content of the ovarian follicle (follicular fluid containing GCs and oocytes) was passed on to a qualified embryologist that extracted all of contained oocytes that were subsequently used in further stages of the IVF procedure (conducted at Division of Infertility and Reproductive Endocrinology, Department of Gynecology, Obstetrics and Gynecological Oncology, Poznan University of Medical Sciences, Poznan, Poland). Meanwhile, the remaining granulosa cell containing follicular fluid, usually discarded after this step, was passed on to the employees of Department of Anatomy, Poznan University of Medical Sciences, in which the further research was conducted. Patients with a potential risk of inadequate ovarian stimulation-according to Bologna criteria of poor ovarian responders, published by European Society of Human Reproduction and Embryology (ESHRE) in 2011 (26) have been excluded, accepting serum antimullerian hormone (AMH) $0,7 \mathrm{ng} / \mathrm{ml}$ as a cut-off value. Moreover, patients with serum level of FSH above $15 \mathrm{mU} / \mathrm{ml}$ on the 2 nd-3rd day of the cycle, as well as patients with polycystic ovary syndrome and endometriosis, have also been excluded from the study. Only ovarian GCs, usually a part of the discarded remnant material of the IVF procedure, were used in the research. This study has been approved with resolution 558/17 by Poznan University of Medical Sciences Bioethical Committee. All participants gave their written informed consent for use of their material in research.

Primary cell culture. The GCs, suspended in follicular fluid, were washed twice by centrifugation at $200 \mathrm{x}$ g for $10 \mathrm{~min}$ at RT. Medium consisted of Dulbecco's Modified Eagle's Medium (DMEM, Sigma-Aldrich Co.; Merck KGaA), $2 \%$ fetal bovine serum FBS (FBS; Sigma-Aldrich; Merck KGaA), 4 mM L-glutamine (Invitrogen; Thermo Fisher Scientific, Inc.), $10 \mathrm{mg} / \mathrm{ml}$ gentamycin (Invitrogen; Thermo Fisher Scientific, Inc.), $10,000 \mathrm{U} / \mathrm{ml}$ penicillin, and $10,000 \mu \mathrm{g} / \mathrm{ml}$ streptomycin (Invitrogen; Thermo Fisher Scientific, Inc.). Cells were cultivated at $37^{\circ} \mathrm{C}$ under aerobic conditions $\left(5 \% \mathrm{CO}_{2}\right)$ in $25 \mathrm{~cm}^{3}$ culture flasks (Corning Inc., Corning, NY, USA). The cells were passaged upon reaching $90 \%$ confluence; they were detached with $0.05 \%$ trypsin-EDTA (Invitrogen; Thermo Fisher Scientific, Inc.) for 1-2 min and counted using an ADAM Cell Counter and Viability Analyzer (Bulldog Bio). After counting, the cells were seeded onto a number of flasks appropriate for total cell number $\left(2-3 \times 10^{6}\right.$ cells per $25 \mathrm{~cm}^{3}$ flask). GCs were then cultivated for 30 days, the morphology was checked daily and photographed using an Olympus inverted microscope (Olympus). The medium was changed twice a week. Finally, total RNA was isolated from GCs after 1, 7, 15 and 30 days. The viability of each collected sample was tested using the ADAM CCVA, with only samples containing 95\% or more viable cells used for subsequent molecular analyses.

Total RNA isolation. RNA was isolated at 4 time periods, after $1,7,15$, and 30 days cultivation. The Chomczyński-Sacchi method was used to isolate the total RNA (27). The GCs were suspended in $1 \mathrm{ml}$ mixture of guanidine thiocyanate and 
phenol in monophase solution (TRI Reagent ${ }^{\circledR}$; Sigma-Aldrich; Merck KGaA). In the next step, the chloroform was added and centrifuged to separate 3 phases. RNA has been located in an aqueous phase. The resulting RNA was intact with no contaminating DNA and protein. In the last step, the RNA has been precipitated with 2-propanol (Sigma-Aldrich, cat. no. I9516), in amount accurate per $1 \mathrm{ml}$ of TRI-reagent and has been washed with $75 \%$ ethanol. Resulting RNA has been used for further analysis. The total mRNA was determined from the optical density at $260 \mathrm{~nm}$ and the RNA purity was estimated using the 260/280 nm absorption ratio (NanoDrop spectrophotometer, Thermo Scientific). Samples with absorbance ratio 260/280 greater than 1.8 have been used to the presented study.

Microarray expression analysis. The microarray procedure was conducted according to protocols used in previous studies of our team (5,28-32). Total RNA (100 ng) from each pooled sample was subjected to two rounds of sense cDNA amplification (Ambion ${ }^{\circledR}$ WT Expression Kit). The obtained cDNA was used for biotin labelling and fragmentation using Affymetrix GeneChip ${ }^{\circledR}$ WT Terminal Labeling and Hybridization (Affymetrix). Biotin-labelled fragments of cDNA $(5.5 \mu \mathrm{g})$ were hybridized to the Affymetrix ${ }^{\circledR}$ Human Genome U219 Array $\left(48^{\circ} \mathrm{C} / 20 \mathrm{~h}\right)$. Microarrays were then washed and stained according to the technical protocol using the Affymetrix GeneAtlas Fluidics Station. The array strips were scanned employing Imaging Station of the GeneAtlas System. Preliminary analysis of the scanned chips was performed using Affymetrix GeneAtlas ${ }^{\mathrm{TM}}$ Operating Software. The quality of gene expression data was confirmed according to the quality control criteria provided by the software. The obtained CEL files were imported into downstream data analysis software.

Reverse transcription-quantitative PCR (RT-qPCR). The RT-qPCR method was performed to confirm the results obtained in the analysis of expression microarrays. Three genes were selected from each heatmap: The ones showing highest, lowest, and most intermediate-level of expression. Changes in the level of expression of those genes were then examined. In each group, three independent samples were analyzed, each coming from a different patient (referred to as a biological repeat). Each test was performed in 3 replicates. Reverse transcription was based on the protocols and reagents of SABiosciences (RT ${ }^{2}$ First Stand Kit-330401), using a Veritimer 96 well Thermal Cycler. $1 \mu \mathrm{g}$ of each gene's RNA transcript was used for reverse transcription. qPCR was performed using the Light Cycler $^{\circledR} 96$ (Roche Diagnostic GmbH, Germany), RT ${ }^{2}$ SYBR $^{\circledR}$ Green ROX $^{\text {TM }}$ qPCR Master Mix (Qiagen Sciences, Inc.,) and sequence-specific primers (Table I). Glyceraldehyde-3-phosphate dehydrogenase (GAPDH), $\beta$-actin (ACTB) and hypoxanthine phosphoribosyltransferase 1 (HRPT1) were used as reference genes. Gene expression was analyzed using the $2^{-\Delta \Delta \mathrm{Cq}}$ method (33). The qPCR starters were designed using the Primer3Plus software (http://primer3plus.com/cgi-bin/dev/primer3plus.cgi).

Statistical analysis. All of the presented analyses and graphs were performed using Bioconductor and $\mathrm{R}$ programming languages. Each CEL file was merged with a description file.
In order to correct background, normalize, and summarize results, we used the Robust Multiarray Averaging (RMA) algorithm. To determine the statistical significance of the analyzed genes, moderated t-statistics from the empirical Bayes method were performed. The obtained P-value was corrected for multiple comparisons using Benjamini and Hochberg's false discovery rate. The selection of significantly altered genes was based on a P-value beneath 0.05 and expression higher than two-fold. The differentially expressed gene list (separated for up- and down-regulated genes) was uploaded to the DAVID software (Database for Annotation, Visualization and Integrated Discovery) (34).

Subsequently, sets of differentially expressed genes from selected GO BP terms were applied to STRING software (Search Tool for the Retrieval of Interacting Genes/Proteins) for interaction prediction. STRING is a huge database containing information about protein/gene interactions, including experimental data, computational prediction methods and public text collections.

Finally, the functional interactions between genes that belong to the chosen GO BP terms were investigated by REACTOME FIViz application to the Cytoscape 3.6.0 software. The ReactomeFIViz app is designed to find pathways and network patterns related to cancer and other types of diseases. This app accesses the pathways stored in the Reactome database, allowing to do pathway enrichment analysis for a set of genes, visualize hit pathways using manually laid-out pathway diagrams directly in Cytoscape, and investigate functional relationships among genes in hit pathways. The app can also access the Reactome Functional Interaction (FI) network, a highly reliable, manually curated pathway-based protein functional interaction network covering over $60 \%$ of human proteins.

Additionally, a statistical analysis of the RT-qPCR results (dependent sample Student's t-test corrected for multiple comparisons using Benjamini and Hochberg's false discovery rate) was conducted for every analyzed sample mean. Samples were only considered further if $\mathrm{P}<0.05$. This analysis employed the Real Statistics Resource Pack add-on for MS Excel 2016 (Microsoft Corporation).

\section{Results}

Whole transcriptome profiling by Affymetrix microarray allowed us to analyze the expression changes in GCs, after 1, 7, 15 and 30 days of culture. By Affymetrix ${ }^{\circledR}$ Human HgU 219 Array, we examined the expression of 22480 transcripts. Genes with a fold change higher then abs (2) and with a corrected P-value lower than 0.05 were considered as differentially expressed. This set of genes consisted of 2278 different transcripts.

DAVID (Database for Annotation, Visualization and Integrated Discovery) software was used for extraction of the gene ontology biological process terms (GO BP). Up and down-regulated gene sets were subjected to the DAVID search separately and only gene sets of adj. P-values $<0.05$ were selected. The DAVID software analysis showed that differentially expressed genes belonged to 582 Gene Ontology Biological Process (GO BP) terms and 45 KEGG pathways. In this report, we focused on 'osteoblast differentiation' GO BP term. This set of genes was subjected to hierarchical 
Table I. Oligonucleotide sequences of primers used for RT-qPCR analysis.

\begin{tabular}{|c|c|c|}
\hline Gene name & Primer sequence $\left(5^{\prime}-3^{\prime}\right)$ & Product size (bp) \\
\hline \multirow[t]{2}{*}{ SYNCRIP } & F: TGTGGGAAAGATCCCAAGAG & 231 \\
\hline & R: TTGGCAACTGAGATGCAGAC & \\
\hline \multirow[t]{2}{*}{ MRC2 } & F: CACCAAACTCCGGTATTGCT & 189 \\
\hline & R: TGGATCTCGGGTTCTGATTC & \\
\hline \multirow[t]{2}{*}{ RRAS2 } & F: AGCACGGCAGCTTAAGGTAA & 165 \\
\hline & R: TGGCAGCCTTTCTTGTCTTT & \\
\hline \multirow[t]{2}{*}{ TPM4 } & F: TTGAGGAGGAGTTGGACAGG & 159 \\
\hline & R: GCTGCATCTCCTGAATCTCC & \\
\hline \multirow[t]{2}{*}{ SPP1 } & F: GCCGAGGTGATAGTGTGGTT & 242 \\
\hline & R: GTGGGTTTCAGCACTCTGGT & \\
\hline \multirow[t]{2}{*}{ FHL2 } & F: CTCATCCAAGTGCCAGGAAT & 175 \\
\hline & R: CTCATAGCAGGGCACACAGA & \\
\hline \multirow[t]{2}{*}{ SKI } & F: CAGCAGAAGGTTGTGAGCAG & 165 \\
\hline & R: CGAGTCCTTGTCCTCCTCTG & \\
\hline \multirow[t]{2}{*}{ EPHA2 } & F: GAGGGCGTCATCTCCAAATA & 236 \\
\hline & R: TCAGACACCTTGCAGACCAG & \\
\hline \multirow[t]{2}{*}{ CYR61 } & F: CTCCCTGTTTTTGGAATGGA & 241 \\
\hline & R: TGGTCTTGCTGCATTTCTTG & \\
\hline \multirow[t]{2}{*}{ CDK6 } & F: TGCACAGTGTCACGAACAGA & 150 \\
\hline & R: ACCTCGGAGAAGCTGAAACA & \\
\hline \multirow[t]{2}{*}{ SFRP1 } & F: CGAGTTTGCACTGAGGATGA & 190 \\
\hline & R: GAAGTGGTGGCTGAGGTTGT & \\
\hline \multirow[t]{2}{*}{ CTHRC1 } & F: GCTCACTTCGGCTAAAATGC & 165 \\
\hline & R: CCACAGAAGAAGTGCGATGA & \\
\hline \multirow[t]{2}{*}{ CREB3L1 } & F: AGGTGGAGACCCTGGAGAAT & 223 \\
\hline & R: AGGGGGTCTTCCTTCACAGT & \\
\hline \multirow[t]{2}{*}{ GLI2 } & F: CACCAACCAGAACAAGCAGA & 246 \\
\hline & R: ACCTCAGCCTCCTGCTTACA & \\
\hline \multirow[t]{2}{*}{ IGFBP5 } & F: GAGCTGAAGGCTGAAGCAGT & 237 \\
\hline & R: GAATCCTTTGCGGTCACAAT & \\
\hline \multirow[t]{2}{*}{ TWIST } & F: GTCCGCAGTCTTACGAGGAG & 159 \\
\hline & R: CCAGCTTGAGGGTCTGAATC & \\
\hline \multirow[t]{2}{*}{ BMP4 } & F: CTGGTCCACCACAATGTGAC & 162 \\
\hline & R: CGATCGGCTAATCCTGACAT & \\
\hline \multirow[t]{2}{*}{ COL1A1 } & F: GTGCTAAAGGTGCCAATGGT & 228 \\
\hline & R: CTCCTCGCTTTCCTTCCTCT & \\
\hline \multirow[t]{2}{*}{ LRRC17 } & F: CAACCCCTGGCACTGTACTT & 225 \\
\hline & R: ACCTCAGGCTTGATGACTGG & \\
\hline \multirow[t]{2}{*}{ GAPDH } & F: TCAGCCGCATCTTCTTTTGC & 90 \\
\hline & R: ACGACCAAATCCGTTGACTC & \\
\hline \multirow[t]{2}{*}{ ACTB } & F: AAAGACCTGTACGCCAACAC & 132 \\
\hline & R: CTCAGGAGGAGCAATGATCTTG & \\
\hline \multirow[t]{2}{*}{ HPRT } & F: TGGCGTCGTGATTAGTGATG & 141 \\
\hline & R: ACATCTCGAGCAAGACGTTC & \\
\hline
\end{tabular}

F, forward; R, reverse. RT-qPCR, reverse transcription-quantitative PCR.

clusterization procedure and presented as a heatmap (Fig. 1). The gene symbols, fold changes in expression, Entrez gene IDs and corrected P-values of these genes were shown in Table II.
STRING interaction network was generated among differentially expressed genes belonging to each of selected GO BP terms. Using such a prediction method provided 
Table II. Gene symbols, fold changes in expression, Entrez gene IDs and corrected P-values of studied genes.

\begin{tabular}{lrcccccc}
\hline Symbol & $\begin{array}{r}\text { Entrez } \\
\text { Gene ID }\end{array}$ & $\begin{array}{c}\text { Fold change } \\
\text { D7/D1 }\end{array}$ & $\begin{array}{c}\text { Fold change } \\
\text { D15/D1 }\end{array}$ & $\begin{array}{c}\text { Fold change } \\
\text { D30/D1 }\end{array}$ & $\begin{array}{c}\text { Adj. P-value } \\
\text { D7/D1 }\end{array}$ & $\begin{array}{c}\text { Adj. P-value } \\
\text { D15/D1 }\end{array}$ & $\begin{array}{c}\text { Adj. P-value } \\
\text { D30/D1 }\end{array}$ \\
\hline SYNCRIP & 10492 & 2.060 & 1.867 & 1.885 & 0.013 & 0.018 & 0.016 \\
MRC2 & 9902 & 2.337 & 2.031 & 1.974 & 0.018 & 0.028 & 0.028 \\
RRAS2 & 22800 & 2.242 & 2.358 & 2.427 & 0.025 & 0.019 & 0.015 \\
TPM4 & 7171 & 2.538 & 2.478 & 2.493 & 0.013 & 0.012 & 0.011 \\
SPP1 & 6696 & 9.788 & 0.953 & 2.840 & 0.028 & 0.965 & 0.188 \\
FHL2 & 2274 & 3.073 & 3.898 & 2.849 & 0.028 & 0.014 & 0.028 \\
SKI & 6497 & 2.463 & 2.503 & 3.342 & 0.003 & 0.002 & 0.001 \\
EPHA2 & 1969 & 4.820 & 2.854 & 3.519 & 0.003 & 0.008 & 0.004 \\
CYR61 & 3491 & 4.318 & 4.249 & 4.154 & 0.001 & 0.001 & 0.001 \\
CDK6 & 1021 & 3.725 & 3.762 & 4.232 & 0.024 & 0.022 & 0.014 \\
SFRP1 & 6422 & 5.257 & 6.419 & 5.765 & 0.009 & 0.006 & 0.006 \\
CTHRC1 & 115908 & 3.349 & 4.023 & 6.926 & 0.040 & 0.023 & 0.007 \\
CREB3L1 & 90993 & 6.916 & 5.727 & 12.541 & 0.004 & 0.005 & 0.001 \\
GLI2 & 2736 & 6.935 & 7.104 & 14.113 & 0.019 & 0.016 & 0.006 \\
IGFBP5 & 3488 & 12.733 & 16.566 & 17.230 & 0.014 & 0.009 & 0.008 \\
TWIST1 & 7291 & 13.411 & 16.061 & 20.741 & 0.001 & 0.001 & 0.001 \\
BMP4 & 652 & 10.489 & 17.221 & 21.243 & 0.020 & 0.010 & 0.007 \\
COL1A1 & 1277 & 8.195 & 19.443 & 85.847 & 0.028 & 0.009 & 0.002 \\
LRRC17 & 10234 & 3.985 & 34.428 & 103.392 & 0.016 & 0.001 & 0.000
\end{tabular}

D, day of in vitro culture.

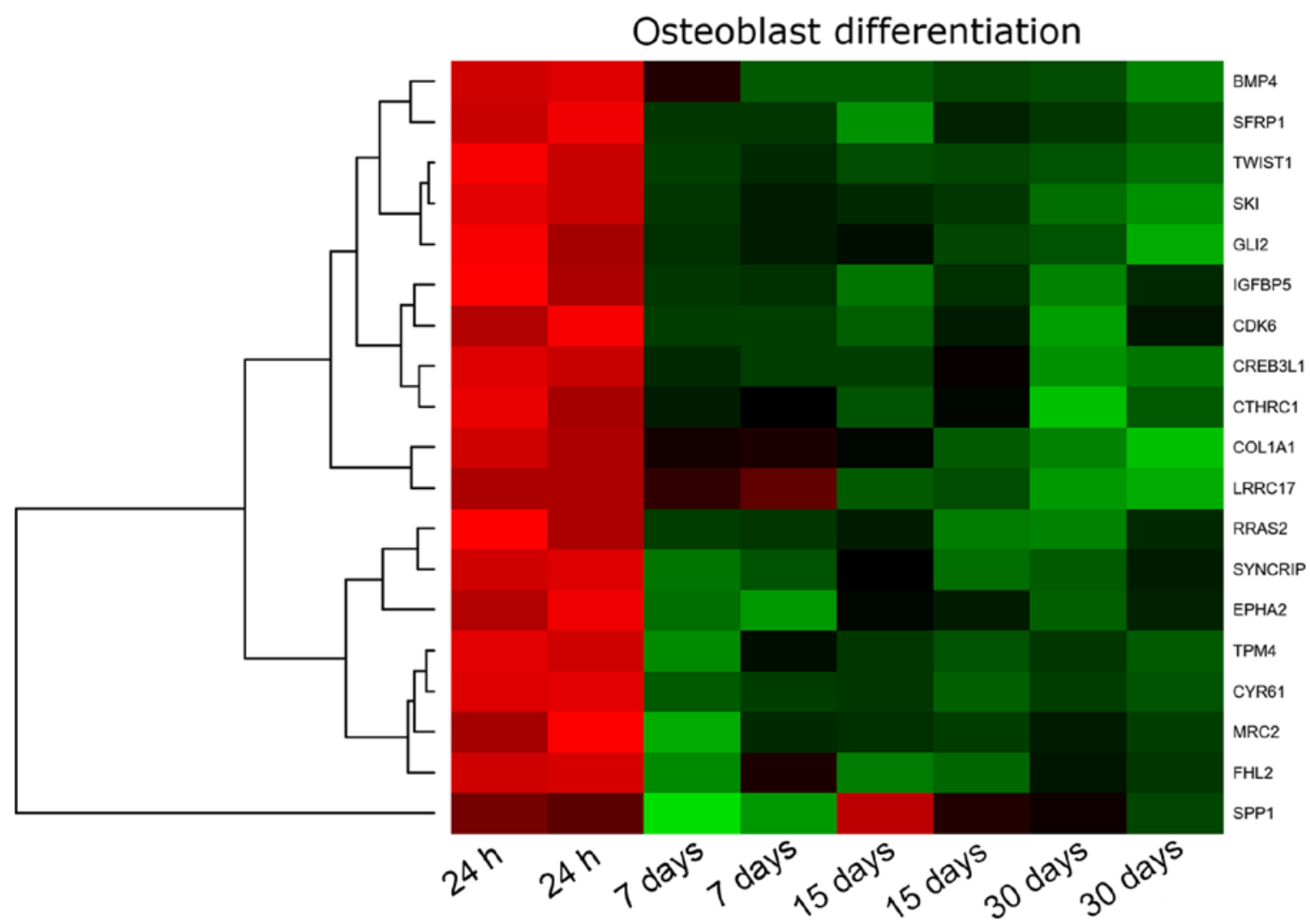

Figure 1. Heat map representation of differentially expressed genes belonging to the 'osteoblast differentiation' Gene Ontology biological process term. Arbitrary signal intensity acquired from microarray analysis is represented by colors. Green represents higher expression, and represents red lower expression. $\log 2$ signal intensity values for any single gene were resized to Row Z-Score scale $(-2$, lowest expression; +2 , highest expression for the single gene). D, days of in vitro culture; $\mathrm{H}$, hours of in vitro culture. 


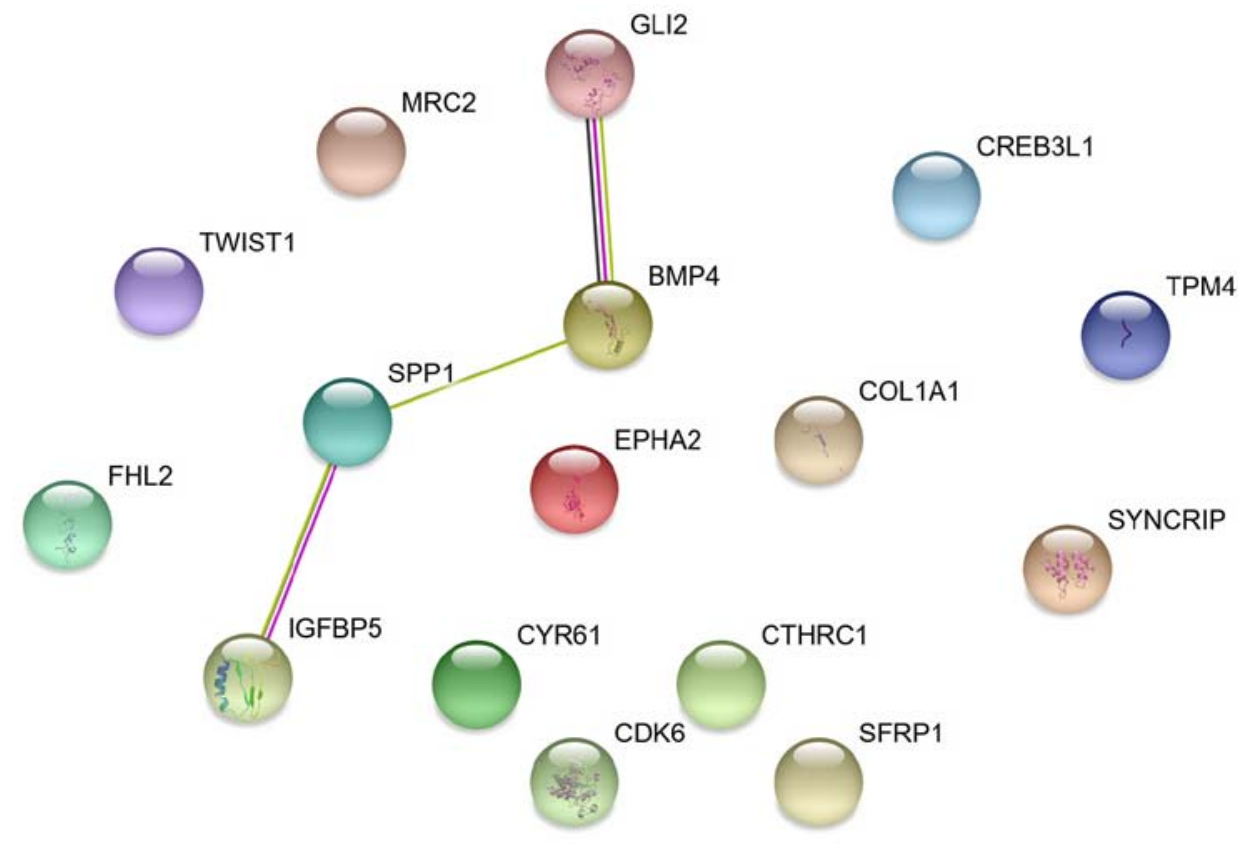

Known interactions

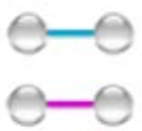

from curated databases

experimentally determined
Predicted interactions

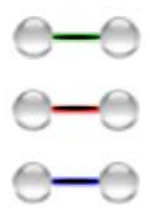

gene neighborhood

gene fusions

gene co-occurrence
Others

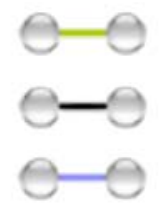

textmining

co-expression

protein homology

Figure 2. STRING-generated interaction network of differentially expressed genes belonging to the 'osteoblast differentiation' Gene Ontology biological process terms. The intensity of the edges reflects the strength of the interaction score.

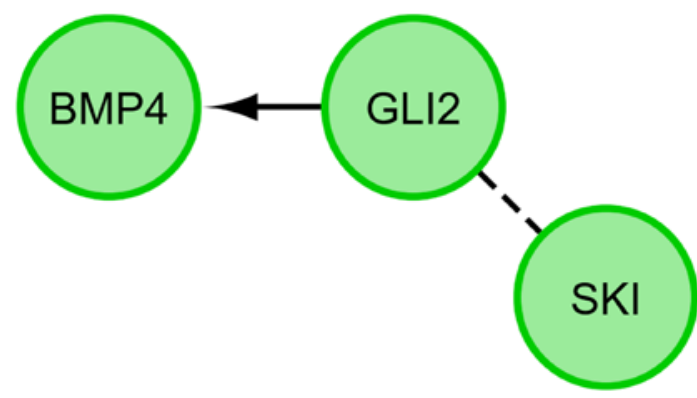

Figure 3. FI between differentially expressed genes belonging to the 'osteoblast differentiation' Gene Ontology biological process terms. '->' represents activating/catalyzing and '---' predicted FIs. BMP4, bone morphogenetic protein 4; FI, functional interaction; GLI2, GLI family zinc finger 2; SKI, SKI proto-oncogene.

us with a molecular interaction network formed between protein products of studied genes (Fig. 2). Finally, we investigated the functional interactions between chosen genes with REACTOME FIViz app to Cytoscape 3.6.0 software. The results were shown in Fig. 3.

RT-qPCR was conducted to validate the results obtained during microarray analysis. The outcomes were presented and compared in a form of a bar graph (Fig. 4).

As can be seen, the direction of changes in expression was confirmed in most examples. Nevertheless, the microarray approach, used to analyze the full transcriptome of the cells, is largely qualitative, which can be observed as validation of the results with quantitative RT-qPCR in two examples gives variable results. For SPP1 transcript expression level, microarray results indicate downregulation in 15 days of cell culture, while RT-qPCR results give a different direction of changes. A similar situation may be observed for RRAS1 mRNA levels. This might be due to the fact that the microarrays account for multiple available exons forming many variants of the expressed gene, which is not usually the case with RT-qPCR, as it probes for a specific gene sequence. Likewise, the scale of differences in transcript levels varied between both of the methods analysed.

\section{Discussion}

The process of MSC differentiation towards osteoblasts is regulated by a number of transcription factors, the list of which is still incomplete and systematically supplemented and updated $(35,36)$. During the development of the skeleton, MSCs may give rise to two cell lines: i) Osteoblasts and ii) chondroblasts. The dual development potential of MSC is made possible due to expression of two basic bone formation regulators: Runx-2 (CBFA-core binding factor Ralpha/osteoblast-specific factor 2-OSF-2) and SOX-9. The further way of differentiation (towards osteoblasts or chondroblasts) is decided by the inclusion of further transcription factors. Osterix (OSX), and Runx-2 are some of the factors that facilitate the osteogenesis process $(37,38)$. The increase in expression of OSX factor influences the increase of expression 


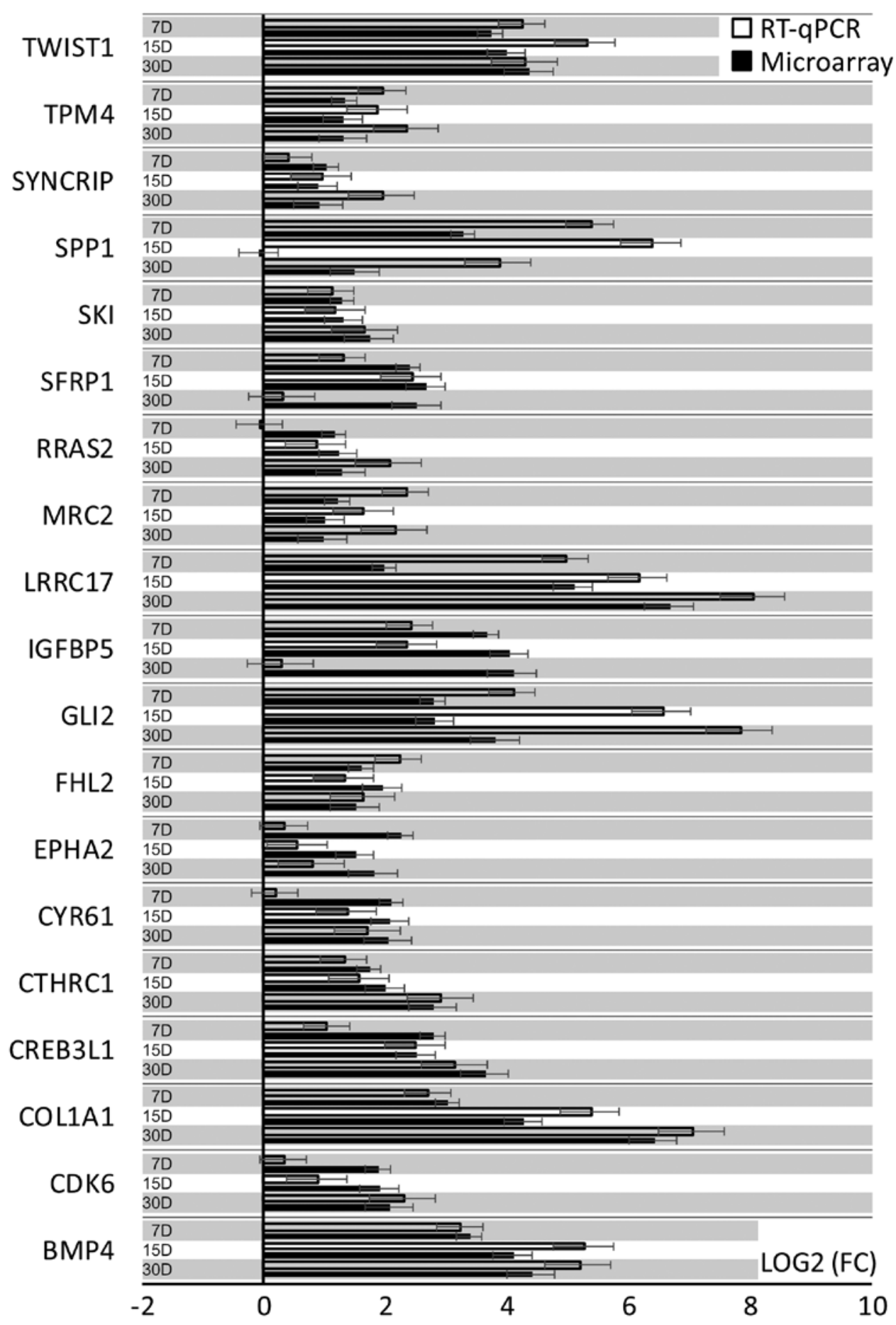

Figure 4. Results of the RT-qPCR validation of microarray results. Presented as a bar graph. FC, was presented in its logarithmic form [Log(FC)] to provide clear comparability of the results. The error bars represent the SEM. All presented sample means were deemed to be statistically significant $(\mathrm{P}<0.05)$. $\mathrm{D}$, days of in vitro culture; FC, fold change; RT-qPCR, reverse transcription-quantitative PCR.

and secretion of osteoblast-specific proteins-collagen type I, osteopontin, sialoprotein and alkaline phosphatase (39). Other important factors regulating osteoblastogenesis are involved in the Wnt/ $\beta$-catenin signalling pathway. Activation of Wnt pathway proteins stimulates osteoblast proliferation $(36,38)$. Bone morphogenetic proteins (BMPs) are yet another important group of factors regulating the process of osteoblastogenesis. These proteins have a stimulating effect on osteoblast activity through BMP serine-threonine kinase receptors. Many other factors also contribute to the stimulation of osteoblast activity such as parathormone (PTH)-acting via insulin-like growth factor (IGF), dexamethasone, lectin etc. (40-43).

As mentioned above, the literature provides a number of factors that influence the differentiation of MSCs towards osteoblasts in vitro. Many authors indicate that the source of these stem cells is also the ovary. Kossowska-Tomaszczuk et al (21) were the first to suggest that GCs have the potential of stem cells (mesenchymal stem cells), due to the expression of markers characteristic for this type of cells. It was the first to prove that GCs can differentiate into osteoblasts in long-term 

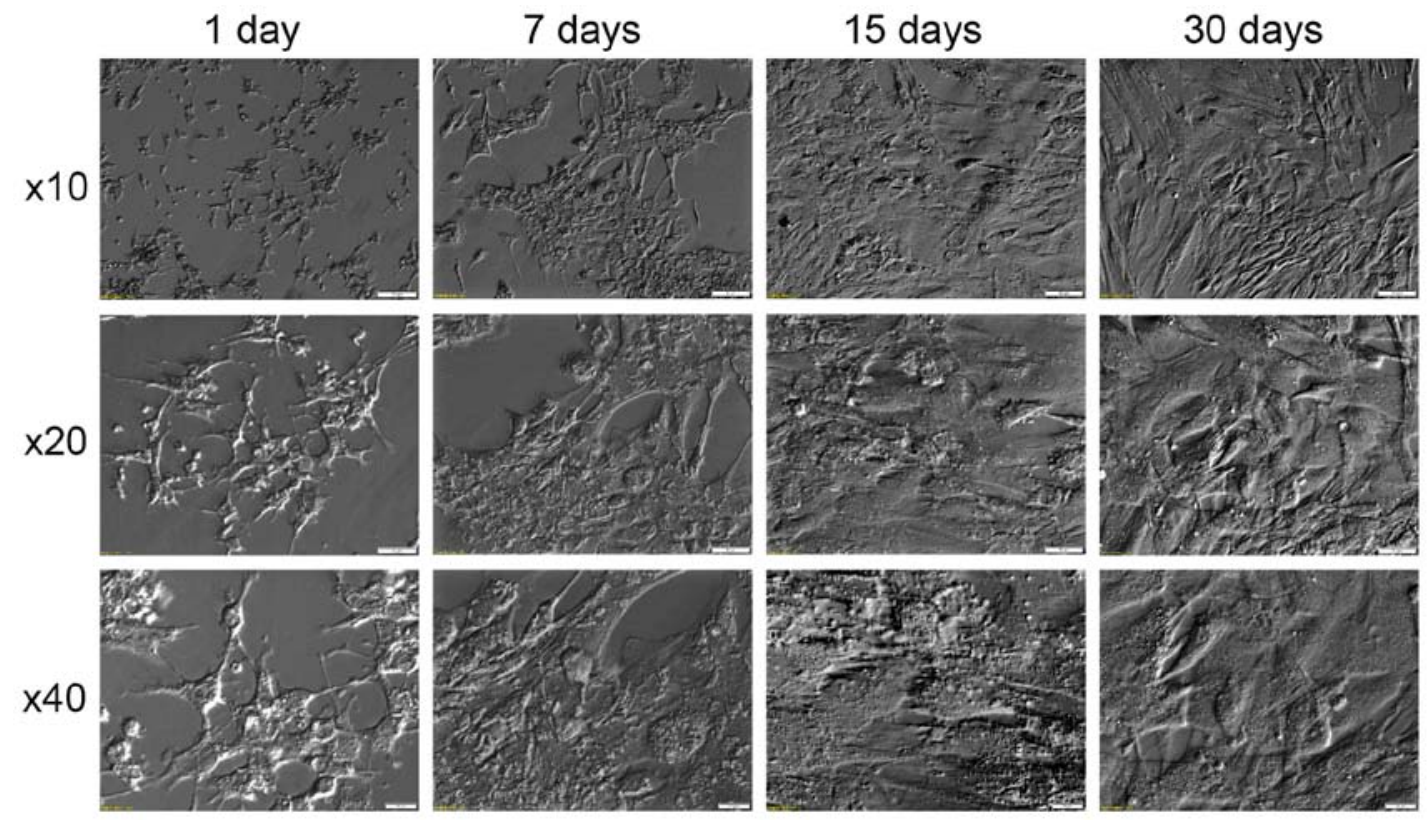

Figure 5. Morphology of human ovarian GCs in long-term in vitro culture. The magnifications are indicated on the left in the figure. Magnification, x10, $\mathrm{x} 20$ and $\mathrm{x} 40$. GCs, granulosa cells.

in vitro culture under the influence of a suitable differentiating medium. GCs thus shed new properties and could be successfully used as a starting material for obtaining stable populations of osteoblasts used in regenerative medicine of skeletal-related disorders $(21,44,45)$. The results of the presented studies confirm the possibility of differentiating GCs towards osteoblasts. We can observe that GCs is subject to such differentiation without differentiating factors constituting the supplement of the culture medium. We can, therefore, conclude that GCs undergoes a number of changes in gene expression during long-term in vitro culture, the effect of which is their entry into the pathway of osteoblast differentiation.

The presented studies also indicate that GCs may differentiate towards osteoblasts under long-term in vitro culture conditions. Moreover, it was shown that GCs express genes characteristic for this process, which can be considered genetic markers of differentiation of GCs towards osteoblasts. GCs in the presented studies were cultivated without the addition of supplements considered necessary for the process of cell differentiation towards osteoblasts. The basal medium did not contain any supplements such as dexamethasone, BMP-2, vitamin D3, ascorbic acid, $\beta$-glycerophosphate, valproic acid, which are considered to be key factors osteoblast differentiation $(15,19,46)$. The results of the presented research on the potential of GCs differentiation towards osteoblasts are confirmed in the literature of recent years $(21,23,44)$.

The 'osteoblast differentiation' ontological group defines a group of genes responsible for the biological process during which the differentiation of less specialized cells towards osteoblasts occurs. The included heat map presents a set of genes that are characteristic of the process of GCs differentiation towards osteoblasts.

As can be seen in the attached table, during the 30-day in vitro culture, the expression of 19 genes is changed, with SYNCRIP, MRC2, RRAS2 and TPM4 exhibiting the lowest expression, and LRRC17, COL1A1, BMP4, TWISTI, IGFBP5,
GLI2, CTHRC1 showing the highest expression. This report is focused on the genes of the highest expression and their mutual relation.

Analyzing the relationships and interactions between the 19 genes of interest, we can only observe some between two pairs of genes (BMP4 and GLI2 and SPPI and IGFBP5).

The highest expression from all genes has been demonstrated by LRRC17 (Leucine-rich repeat containing 17). It is not only one of the genes that regulate the osteoblastogenesis process, but also a gene that is expressed by the ovary. The above result, on one hand, can confirm that the obtained cells are cells derived from the ovary, but on the other hand can be a factor regulating the process of differentiation of GCs towards osteoblasts $(47,48)$. It is a gene that is highly expressed in osteoblasts under physiological conditions (47). The high expression change of this gene during long-term in vitro GC culture indicates that these cells can spontaneously gain osteoblast properties.

Another very important gene demonstrating the differentiation of a given population towards osteoblasts is the expression of the collagen type I gene and protein. The expression of collagen type I is significantly increased after 30 days of GC in vitro culture. We can, therefore, suppose that the process of GCs differentiation towards osteoblasts is also regulated by typical factors of MSC osteoblastogenesis. COL1A1 (Collagen type I alpha 1 chain) is a gene providing inductions for the synthesis of a large molecular molecule called collagen type I. Collagens are a family of proteins that are part of most organs in the human body: They build cartilage, tendons, skin, sclera, and above all bones. Collagen molecules form long fibrils, connected by transverse bonds between them in intercellular spaces. Such structure and interactions between collagen fibres are called cross-linking, which results in the formation of very strong type 1 collagen fibres (49). The expression of the COL1A1 gene indicates that GCs have the potential to differentiate towards the bone tissue. Under physiological conditions, 
the COL1Al gene is not expressed in GCs. Only the presence of collagen type I in the theca cells of the ovarian follicle has been proven $(50,51)$. However, these are not the subject of the research presented. Only GCs building an internal layer of ovarian follicle were used in the study.

Osteogenesis is the process leading to the formation of bone tissue. It begins during the formation of the embryo and continues throughout the entire life of the organism by maintaining a balance between bone formation and resorption (52). Bone morphogenetic proteins belong to the superfamily of TGF- $\beta$ s (Transforming growth factors $\beta$ ). The family of these proteins is responsible for the formation of bone and cartilage in vivo but also fulfils important roles in the female reproductive system $(53,54)$. One of the strongest inductors in bone formation through osteoblast differentiation stimulation is BMP-4. Under physiological conditions, BMP-4 transduced signals through heterodimer formation of Type II and Type I cognate complex (BMPRIA and BMPRIB) through serine/threonine receptors. This leads to phosphorylation of Sma and Mad proteins playing an important role in the differentiation of cells derived from the mesenchymal line (55-57). The group of BMP proteins also plays a role in the regulation of follicular development and has an effect on GCs proliferation and steroidogenesis. Tanwar and Mcfarlane (58) indicate, in their mice studies, that BMP-4 is expressed in the ovary, uterus and oviduct epithelium. It has also been shown that BMP-4 acts as a paracrine/autocrine modulator of steroidogenesis of GCs cells. BMP-4 together with BMP-6, BMP-7 stimulates Smad-1 accumulation and release of estradiol (E2) stimulated by IGF $(59,60)$. Other studies have shown that another types of BMP, above all BMP-15, are necessary for the proper functioning of the reproductive system of the female. It is BMP-15 that affects the proliferation and differentiation of GCs into individual layers within the follicle (61). The presented studies do not clearly indicate whether the expression of BMP-4 is associated with the the process of steroidogenesis occurring in vitro culture or whether this expression is associated with osteogenesis. In a broad sense, we can conclude that the presence of other genes involved in the BMP-4 osteogenesis process could confirm its occurrence in the culture. This conclusion is supported by the expression of the previously mentioned SPP1 gene (secreted phosphoprotein; osteopontin) (62). SPP1 is a gene responsible for the proper bone mineralization in the process of osteogenesis. Kim et al (63) suggested that SPP1 could be a marker of ovarian cancer. Under physiological conditions, the expression of SPP1 increases in the antral follicles (64) suggesting that SPP1 does not indicate a differentiation of GCs towards osteoblasts. Kulterer et al (65) proved that during the differentiation of MSCs towards osteoblasts, SPP1 and COL1A1 are expressed (66). Our research confirms this scheme; however, it should be emphasized that in the presented results P-values were $<0.05$ only after 7 days of culture, bringing their actual significance into question. In addition, another gene supporting the GCs' tendency for osteogenic differentiation in long-term in vitro is the GLI2 (GLI-Kruppel Family Member 2). This gene belongs to the family of zinc finger proteins. Under physiological conditions, the GLI family proteins play an important role in embryonic development. Abnormal operation of these genes causes development defects, eg: Mutations in the GLI2 gene cause defects in the development of the skeleton. In addition, GLI2 has been shown to play a large role in regulating BMP-2 protein expression during osteoblast differentiation (67). The presented research results confirm the relationship between the expression of GLI2 and BMP-4. During the differentiation of GCs towards osteoblasts in long-term in vitro culture, GLI2 may interact with BMP-4 in a positive manner (Figs. 2 and 3).

IGFBP-5 (Insulin-like growth factor-binding protein 5) is another factor involved in the process of osteoblast formation. This substance is detected during osteoblastogenesis. It is most intensively released during the first days of in vitro culture before mature osteoblasts arise. It is known that the amount of this factor decreases during long-term in vitro culture (68). In addition, IGFBP-5 produced by osteoblasts stimulates osteoclastogenesis and thus acts as an osteoblast-osteoclast coupling agent (69). Liu and Ling (70) proved that the rat ovary produces 5 types of IGFBP, including IGFBP-5 in GCs of atretic preantral follicles. In addition, the presented study results suggest that IGFBP5 interacts with the SPP1 gene described above (Fig. 2).

According to the results presented, growth factors such as BMP-4 or IGFBP5 interact with genes that, in addition to their role in the ovary, also play key roles in osteogenesis. Therefore, these factors may be potential regulators of the expression of the above genes, as well as the process of GC differentiation towards osteoblasts. As already mentioned, these genes play a key role in the process of osteoblast differentiation from mesenchymal stem cells. The results of the presented studies therefore suggest one of the probable ways of osteo-differentiation of GCs.

Another gene that is expressed by GCs after 30 days of in vitro culture is TWIST (Transcription Factor TWIST). Under physiological conditions, this gene is expressed in cells that express RUNX2 expression. As mentioned earlier, the RUNX2 gene is involved in the process of osteoblast formation. The basic function of TWIST is the inhibition of the RUNX2 function during skeletogenesis (71). The TWIST expression can, therefore, explain the lack of RUNX2 expression in the presented GCs after 30 days of culture.

Osteoblast differentiation from stem cells is possible thanks to CTHRC1. Wang et al (72) indicated that this gene, under physiological conditions, is involved in bone remodelling, and also shows the presence in osteocytes, bone matrix and periodontal ligament cells in rat. In presented research $\mathrm{CTHRC1}$ has been activated during long-term in vitro culture of GCs.

In addition to gene expression changes observed during the course of the long-term in vitro culture, we have also observed significant changes of morphology. These changes, documented in Fig. 5, show that in the first days of culture the cells assume star-like shape, followed by their elongation and transition into fibroblast like shape in the later stages of culture. Similar results can be found in literature $(22,44)$. This fact can be associated with the assumed loss of granulosa specific gene expression, caused by the absence of the physiological extracellular environment, and assumption of new, culture-specific phenotype. This process is also accompanied by upregulation of expression of non-granulosa specific growth factors (such as BMP4 and IGFBP5), which may further explain the assumption of new morphology. 
Summing up the conducted research, it can be concluded that there is a lot of evidence for the possibility of GC differentiation towards osteoblasts. Obtaining stable cultures of differentiated osteoblasts derived from GCs may find wide application in the treatment of skeletal disorders. However, it needs to be noted that this is an entry level transcriptomic study, which only accounts for the gene changes observed in the granulosa cell culture and refers them to the available literature. Despite that, the presented research is an excellent "signpost" for further, more detailed studies, possibly including comparisons to osteoblasts cultured in similar conditions, or based on proteomic approaches (which are much better translatable to in vivo knowledge). Detailed analysis of pathways involved in the differentiation of GCs towards osteoblasts is required.

\section{Acknowledgements}

Not applicable.

\section{Funding}

The present study was supported by grants from Poznan University of Medical Sciences (grant no. 502-14-02227367-10694) and Polish National Science Centre (grant no. 2018/31/B/NZ5/02475).

\section{Availability of data and materials}

The datasets used and/or analyzed during the current study are available from the corresponding author on reasonable request.

\section{Authors' contributions}

MBrą provided resources (provision of study materials and patients), designed the experiments and methodology, and wrote the original draft of the manuscript. WK performed the investigation (conducted the research and investigation process, performed the experiments, or data/evidence collection), developed the methodology, and wrote the original draft. PC developed the software, created and presented the published work, wrote the initial draft, and performed the formal analysis and visualization. KO conducted the experiments, acquired data and wrote the manuscript. JBT conducted the experiments, acquired data and wrote the manuscript. MJ designed the methodology and created the models. LP designed the study and revised the medical methodology. MBru contributed to medical procedure design and approved the final draft of the manuscript. MN supervised the study, designed the experiments and provided editorial supervision. MZ revised the methodology, analyzed data and approved the final draft of the manuscript. BK conceived the study, contributed to project administration, acted as the senior author and provided major assistance during the study. All authors read and approved the final manuscript.

\section{Ethics approval and consent to participate}

This study has been approved with resolution 558/17 by Poznan University of Medical Sciences Bioethical Committee.
All participants gave their written informed consent for use of their material in research.

\section{Patient consent for publication}

Not applicable.

\section{Competing interests}

The authors declare that they have no competing interests.

\section{References}

1. Zhang H, Vollmer M, De Geyter M, Litzistorf Y, Ladewig A, Dürrenberger M, Guggenheim R, Miny P, Holzgreve W and De Geyter C: Characterization of an immortalized human granulosa cell line (COV434). Mol Hum Reprod 6: 146-153, 2000.

2. Brůcková L, Soukup T, Moos J, Moosová M, Pavelková J, Rezábek K, Vísek B and Mokrý J: The cultivation of human granulosa cells. Acta Medica (Hradec Kralove) 51: 165-172, 2008.

3. Rybska M, Knap S, Jankowski M, Jeseta M, Bukowska D, Antosik P, Nowicki M, Zabel M, Kempisty B and Jaśkowski JM: Characteristic of factors influencing the proper course of folliculogenesis in mammals. Med J Cell Biol 6: 33-38, 2018.

4. Kranc W, Jankowski M, Budna J, Celichowski P, Khozmi R, Bryja A, Borys S, Dyszkiewicz-Konwińska M, Jeseta M, Magas M, et al: Amino acids metabolism and degradation is regulated during porcine oviductal epithelial cells (OECs) primary culture in vitro-signaling pathway activation approach. Med J Cell Biol 6: 18-26, 2018.

5. Rybska M, Knap S, Jankowski M, Jeseta M, Bukowska D, Antosik P, Nowicki M, Zabel M, Kempisty B and Jaśkowski JM: Cytoplasmic and nuclear maturation of oocytes in mammals-living in the shadow of cells developmental capability. Med J Cell Biol 1: 13-17, 2018.

6. Kempisty B, Ziółkowska A, Piotrowska H, Ciesiółka S, Antosik P, Bukowska D, Zawierucha P, Woźna M, Jaśkowski JM, Brüssow KP, et al: Short-term cultivation of porcine cumulus cells influences the cyclin-dependent kinase 4 (Cdk4) and connexin 43 (Cx43) protein expression-a real-time cell proliferation approach. J Reprod Dev 59: 339-345, 2013.

7. Ciesiółka S, Budna J, Jopek K, Bryja A, Kranc W, Chachuła A, Borys S, Dyszkiewicz Konwińska M, Ziółkowska A, Antosik P, et al: Influence of estradiol-17beta on progesterone and estrogen receptor mRNA expression in porcine follicular granulosa cells during short-term, in vitro real-time cell proliferation. Biomed Res Int 2016: 8431018, 2016.

8. Spanel-Borowski K and Sterzik K: Ultrastructure of human preovulatory granulosa cells in follicular fluid aspirates. Arch Gynecol 240: 137-146, 1987.

9. Neubourg DD, Robins A, Fishel S and Gibbon L: Flow cytometric analysis of granulosa cells from follicular fluid after follicular stimulation. Hum Reprod 11: 2211-2214, 1996.

10. Ratajczak MZ and Suszyńska M: Quo vadis regenerative medicine? Acta Haematol Pol 44: 161-170, 2013.

11. Weiss DJ: Concise review: Current status of stem cells and regenerative medicine in lung biology and diseases. Stem Cells 32: 16-25, 2014.

12. Desai TJ, Brownfield DG and Krasnow MA: Alveolar progenitor and stem cells in lung development, renewal and cancer. Nature 507: 190-194, 2014.

13. Matthews VB and Yeoh GC: Liver stem cells. IUBMB Life 57: $549-553,2005$.

14. Murtaugh LC and Kopinke D: Pancreatic Stem Cells. In: StemBook [Internet]. Harvard Stem Cell Institute, Cambridge, MA, 2008.

15. Lee RH, Kim B, Choi I, Kim H, Choi HS, Suh K, Bae YC and Jung JS: Characterization and expression analysis of mesenchymal stem cells from human bone marrow and adipose tissue. Cell Physiol Biochem 14: 311-324, 2004.

16. Pereira LO, Rubini MR, Silva JR, Oliveira DM, Silva ICR, Poças-Fonseca MJ and Azevedo RB: Comparison of stem cell properties of cells isolated from normal and inflamed dental pulps. Int Endod J 45: 1080-1090, 2012. 
17. Karahuseyinoglu S, Kocaefe C, Balci D, Erdemli E and Can A: Functional structure of adipocytes differentiated from human umbilical cord stroma-derived stem cells. Stem Cells 26 682-691, 2008

18. Malekshah AK, Moghaddam AE and Daraka SM: Comparison of conditioned medium and direct co-culture of human granulosa cells on mouse embryo development. Indian J Exp Biol 44 189-192, 2006.

19. Kern S, Eichler H, Stoeve J, Klüter H and Bieback K: Comparative analysis of mesenchymal stem cells from bone marrow, umbilical cord blood, or adipose tissue. Stem Cells 24: 1294-1301, 2006.

20. Rojas M, Xu J, Woods CR, Mora AL, Spears W, Roman J and Brigham KL: Bone marrow-derived mesenchymal stem cells in repair of the injured lung. Am J Respir Cell Mol Biol 33: 145-152, 2005.

21. Kossowska-Tomaszczuk K, De Geyter C, De Geyter M, Martin I, Holzgreve W, Scherberich A and Zhang H: The multipotency of luteinizing granulosa cells collected from mature ovarian follicles. Stem Cells 27: 210-219, 2009.

22. Brevini TA, Pennarossa G, Rahman MM, Paffoni A, Antonini S Ragni G, deEguileor M, Tettamanti $G$ and Gandolfi $F$ : Morphological and molecular changes of human granulosa cells exposed to 5-azacytidine and addressed toward muscular differentiation. Stem Cell Rev Rev 10: 633-642, 2014

23. Aghadavod E, Zarghami N, Farzadi L, Zare M, Barzegari A Movassaghpour AA and Nouri M: Isolation of granulosa cells from follicular fluid; applications in biomedical and molecular biology experiments. Adv Biomed Res 4: 250, 2015.

24. Kranc W, Brązert M, Budna J, Celichowski P, Bryja A Nawrocki MJ, Ożegowska K, Jankowski M Chermuła B, Dyszkiewicz-Konwińska M, et al: Genes responsible for proliferation, differentiation, and junction adhesion are significantly up-regulated in human ovarian granulosa cells during a long-term primary in vitro culture. Histochem Cell Biol 151: 125-143, 2019.

25. Kranc W, Brazert M, Ożegowska K, Nawrocki MJ, Budna J, Celichowski P, Dyszkiewicz-Konwińska M, Jankowski M, Jeseta M, Pawelczyk L, et al: Expression profile of genes regulating steroid biosynthesis and metabolism in human ovarian granulosa cells-A primary culture approach. Int J Mol Sci 18: pii E2673, 2017.

26. Ferraretti AP, La Marca A, Fauser BC, Tarlatzis B, Nargund G and Gianaroli L; ESHRE working group on Poor Ovarian Response Definition: ESHRE consensus on the definition of 'poor response' to ovarian stimulation for in vitro fertilization: The Bologna criteria. Hum Reprod 26: 1616-1624, 2011

27. Chomczynski $P$ and Sacchi N: Single-step method of RNA isolation by acid guanidinium thiocyanate-phenol-chloroform extraction. Anal Biochem 162: 156-159, 1987.

28. Kranc W, Brazert M, Ożegowska K, Budna-Tukan J, Celichowski P, Jankowski M, Bryja A, Nawrocki MJ, Popis M, Jeseta M and Pawelczyk L: Response to abiotic and organic substances stimulation belongs to ontologic groups significantly up-regulated in porcine immature oocytes. Med J Cell Biol 6: 91-100, 2018.

29. Bryja A, Dyszkiewicz-Konwińska M, Jankowski M, Celichowski P, Stefańska K, Chamier-Gliszczyńska A, Popis M Mehr K, Bukowska D, Antosik P, et al: Ion homeostasis and transport are regulated by genes differentially expressed in porcine buccal pouch mucosal cells during long-term culture in vitro-a microarray approach. Med J Cell Biol 6: 75-82, 2018.

30. Chamier-Gliszczyńska A, Brązert M, Sujka-Kordowska P, Popis M, Ożegowska K, Stefańska K, Kocherova I, Celichowski P, Kulus M, Bukowska D, et al: Genes involved in angiogenesis and circulatory system development are differentially expressed in porcine epithelial oviductal cells during long-term primary in vitro culture-a transcriptomic study. Med J Cell Biol 6 : $163-173,2018$

31. Stefańska K, Chamier-Gliszczyńska A, Jankowski M, Celichowski P, Kulus M, Rojewska M, Antosik P, Bukowska D, Bruska M, Nowicki M, et al: Epithelium morphogenesis and oviduct development are regulated by significant increase of expression of genes after long-term in vitro primary culture - a microarray assays. Med J Cell Biol 6: 195-204, 2018.

32. Nawrocki MJ, Celichowski P, Jankowski M, Kranc W, Bryja A, Borys-Wójcik S, Jeseta M, Antosik P, Bukowska D, Brusk M, et al: Ontology groups representing angiogenesis and blood vessels development are highly up-regulated during porcine oviductal epithelial cells long-term real-time proliferation-a primary cell culture approach. Med J Cell Biol 6: 186-194, 2018.

33. Livak KJ and Schmittgen TD: Analysis of relative gene expression data using real-time quantitative PCR and the 2(-Delta Delta C(T)) method. Methods 25: 402-408, 2001
34. Huang DW, Sherman BT, Tan Q, Kir J, Liu D, Bryant D, Guo Y, Stephens R, Baseler MW, Lane HC and Lempicki RA: DAVID Bioinformatics resources: Expanded annotation database and novel algorithms to better extract biology from large gene lists. Nucleic Acids Res 35 (Web Server Issue): W169-W175, 2007.

35. Rahman MS, Akhtar N, Jamil HM, Banik RS and Asaduzzaman SM: TGF-b/BMP signaling and other molecular events: Regulation of osteoblastogenesis and bone formation. Bone Res 3: 15005, 2015.

36. Zuo C, Huang Y, Bajis R, Sahih M, Li YP, Dai K and Zhang X: Osteoblastogenesis regulation signals in bone remodeling. Osteoporos Int 23: 1653-1663, 2012.

37. Akiyama H, Kim JE, Nakashima K, Balmes G, Iwai $\mathrm{N}$, Deng JM, Zhang Z, Martin JF, Behringer RR, Nakamura T and de Crombrugghe B: Osteo-chondroprogenitor cells are derived from Sox9 expressing precursors. Proc Natl Acad Sci USA 102: 14665-14670, 2005.

38. Bennett CN, Longo KA, Wright WS, Suva LJ, Lane TF, Hankenson KD and MacDougald OA: Regulation of osteoblastogenesis and bone mass by Wnt10b. Proc Natl Acad Sci USA 102: 3324-3329, 2005.

39. Cao Y, Zhou Z, de Crombrugghe B, Nakashima K, Guan H, Duan X, Jia SF and Kleinerman ES: Osterix, a transcription factor for osteoblast differentiation, mediates antitumor activity in murine osteosarcoma. Cancer Res 65: 1124-1128, 2005.

40. Sánchez-Duffhues G, Hiepen C, Knaus P and ten Dijke P: Bone morphogenetic protein signaling in bone homeostasis. Bone 80 : 43-59, 2015.

41. Yuasa M, Yamada T, Taniyama T, Masaoka T, Xuetao W, Yoshii T, Horie M, Yasuda H, Uemura T, Okawa A and Sotome S: Dexamethasone enhances osteogenic differentiation of bone marrow- and muscle-derived stromal cells and augments ectopic bone formation induced by bone morphogenetic protein-2. PLoS One 10: e0116462, 2015

42. Włodarski KH, Galus R, Brodzikowska A and Włodarski PK: Sclerostin, an osteocytes-derived bone-forming inhibitor. Pol Orthop Traumatol 78: 151-154, 2013.

43. Włodarski K and Włodarski P: Leptin as a modulator of osteogenesis. Ortop Traumatol Rehabil 11: 1-6, 2009.

44. Kossowska-Tomaszczuk K and De Geyter C: Cells with stem cell characteristics in somatic compartments of the ovary. Biomed Res Int 2013: 310859, 2013.

45. Kossowska-Tomaszczuk K, Pelczar P, Güven S, Kowalski J, Volpi E, De Geyter C and Scherberich A: A novel three-dimensional culture system allows prolonged culture of functional human granulosa cells and mimics the ovarian environment. Tissue Eng Part A 16: 2063-2073, 2010.

46. Chamberlain G, Fox J, Ashton B and Middleton J: Concise Review: Mesenchymal stem cells: Their phenotype, differentiation capacity, immunological features, and potential for homing. Stem Cells 25: 2739-2749, 2007.

47. Kim T, Kim K, Lee SH, So HS, Lee J, Kim N and Choi Y: Identification of LRRc17 as a negative regulator of receptor activator of NF-kappaB ligand (RANKL)-induced osteoclast differentiation. J Biol Chem 284: 15308-15316, 2009.

48. Coveney C, Boocock DJ, Rees RC, Deen S and Ball GR: Data mining of gene arrays for biomarkers of survival in ovarian cancer. Microarrays (Basel) 4: 324-338, 2015.

49. Saito M and Marumo K: Collagen cross-links as a determinant of bone quality: A possible explanation for bone fragility in aging, osteoporosis, and diabetes mellitus. Osteoporos Int 21: 195-214, 2010.

50. Hatzirodos N, Hummitzsch K, Irving-Rodgers HF, Harland ML, Morris SE and Rodgers RJ: Transcriptome profiling of granulosa cells from bovine ovarian follicles during atresia. BMC Genomics 15: 40, 2014

51. Zhao Y and Luck MR: Gene expression and protein distribution of collagen, fibronectin and laminin in bovine follicles and corpora lutea. J Reprod Fertil 104: 115-123, 1995.

52. Luyten FP, Cunningham NS, Ma S, Muthukumaran N, Hammonds RG, Nevins WB, Woods WI and Reddi AH: Purification and partial amino acid sequence of osteogenin, a protein initiating bone differentiation. J Biol Chem 264 13377-13380, 1989.

53. Bandyopadhyay A, Tsuji K, Cox K, Harfe BD, Rosen V and Tabin CJ: Genetic analysis of the roles of BMP2, BMP4, and BMP7 in limb patterning and skeletogenesis. PLoS Genet 2: e216, 2006 . 
54. Bayne RA, Donnachie DJ, Kinnell HL, Childs AJ and Anderson RA: BMP signalling in human fetal ovary somatic cells is modulated in a gene-specific fashion by GREM1 and GREM2. Mol Hum Reprod 22: 622-633, 2016.

55. Chang SF, Chang TK, Peng HH, Yeh YT, Lee DY, Yeh CR, Zhou J, Cheng CK, Chang CA and Chiu JJ: BMP-4 induction of arrest and differentiation of osteoblast-like cells via p21 CIP1 and p27 KIP1 regulation. Mol Endocrinol 23: 1827-1838, 2009.

56. Fujii M, Takeda K, Imamura T, Aoki H, Sampath TK, Enomoto S, Kawabata M, Kato M, Ichijo H and Miyazono K: Roles of bone morphogenetic protein type I receptors and Smad proteins in osteoblast and chondroblast differentiation. Mol Biol Cell 10: 3801-3813, 1999

57. Yamaguchi A, Komori T and Suda T: Regulation of osteoblast differentiation mediated by bone morphogenetic proteins, hedgehogs, and Cbfa1. Endocr Rev 21: 393-411, 2000.

58. Tanwar PS and Mcfarlane JR: Dynamic expression of bone morphogenetic protein 4 in reproductive organs of female mice. Reproduction 142: 573-579, 2011.

59. Glister C, Kemp CF and Knight PG: Bone morphogenetic protein (BMP) ligands and receptors in bovine ovarian follicle cells: Actions of BMP-4, -6 and -7 on granulosa cells and differential modulation of Smad-1 phosphorylation by follistatin. Reproduction 127: 239-254, 2004.

60. Dooley CA, Attia GR, Rainey WE, Moore DR and Carr BR: Bone morphogenetic protein inhibits ovarian androgen production. J Clin Endocrinol Metab 85: 3331-3337, 2000.

61. Moore RK, Otsuka F and Shimasaki S: Molecular basis of bone morphogenetic protein-15 signaling in granulosa cells. J Biol Chem 278: 304-310, 2003.

62. Harvey NT, Hughes JN, Lonic A, Yap C, Long C, Rathjen PD and Rathjen J: Response to BMP4 signalling during ES cell differentiation defines intermediates of the ectoderm lineage. J Cell Sci 123: 1796-1804, 2010.

63. Kim JH, Skates SJ, Uede T, Wong KK, Schorge JO, Feltmate CM, Berkowitz RS, Cramer DW and Mok SC: Osteopontin as a potential diagnostic biomarker for ovarian cancer. JAMA 287: 1671-1679, 2002

64. Skinner MK, Schmidt M, Savenkova MI, Sadler-Riggleman I and Nilsson EE: Regulation of granulosa and theca cell transcriptomes during ovarian antral follicle development. Mol Reprod Dev 75: 1457-1472, 2008.
65. Kulterer B, Friedl G, Jandrositz A, Sanchez-Cabo F, Prokesch A, Paar C, Scheideler M, Windhager R, Preisegger KH and Trajanoski Z: Gene expression profiling of human mesenchymal stem cells derived from bone marrow during expansion and osteoblast differentiation. BMC Genomics 8: 70, 2007.

66. Bilousova G, Jun DH, King KB, De Langhe S, Chick WS, Torchia EC, Chow KS, Klemm DJ, Roop DR and Majka SM: Osteoblasts derived from induced pluripotent stem cells form calcified structures in scaffolds both in vitro and in vivo. Stem Cells 29: 206-216, 2011.

67. Zhao M, Qiao M, Harris SE, Chen D, Oyajobi BO and Mundy GR: The zinc finger transcription factor Gli2 mediates bone morphogenetic protein 2 expression in osteoblasts in response to hedgehog signaling. Mol Cell Biol 26: 6197-6208, 2006.

68. Thrailkill KM, Quarles LD, Nagase H, Suzuki K, Serra DM and Fowlkes JL: Characterization of insulin-like growth factor-binding protein 5-degrading proteases produced throughout murine osteoblast differentiation. Endocrinology 136: 3527-3533, 1995 .

69. Peruzzi B, Cappariello A, Del Fattore A, Rucci N, De Benedetti F and Teti A: c-Src and IL-6 inhibit osteoblast differentiation and integrate IGFBP5 signalling. Nat Commun 3: 630, 2012.

70. Liu XJ and Ling N: Regulation of IGFBP-4 and -5 expression in rat granulosa cells. Adv Exp Med Biol 343: 367-376, 1994.

71. Bialek P, Kern B, Yang X, Schrock M, Sosic D, Hong N, Wu H, Yu K, Ornitz DM, Olson EN, et al: A twist code determines the onset of osteoblast differentiation. Dev Cell 6: 423-435, 2004.

72. Wang C, Gu W, Sun B, Zhang Y, Ji Y, Xu X and Wen Y: CTHRC1 promotes osteogenic differentiation of periodontal ligament stem cells by regulating TAZ. J Mol Histol 48: 311-319, 2017.

This work is licensed under a Creative Commons Attribution-NonCommercial-NoDerivatives 4.0 International (CC BY-NC-ND 4.0) License. 